\title{
LIXISENATIDE EFFECTS ON LIVER FUNCTION, LIPIDS AND BLOOD PRESSURE LEVELS
}

M. Mar Roca-Rodríguez1, Gonzalo Piédrola-Maroto2, María Teresa Muros de Fuentes2, Miguel Quesada-Charneco3, Silvia

Maraver-Selfa4, M José Tapia-Guerrero4, Daniel Cepero-García5, Rosa Orduña-Espinosa3, Joaquín Pechuán-Asensio6, Elena Ferrándiz-Millón5, Purificación Galera-Martínez2, Mercedes Vázquez-Gutiérrez5, Isabel Mancha-Doblas4.

\section{ECE2016}

28 - 31 May

Munich

Germany

1 Department of Endocrinology, La Linea Hospital, Cadiz, Spain. 2 Department of Endocrinology, Virgen de las Nieves Hospital, Granada, Spain. 3 Department of Endocrinology, San Cecilio Hospital, Granada, Spain.4Department of Endocrinology, Virgen de la Victoria and Regional Hospitals, Malaga, Spain.5Department of Endocrinology, Torrecardenas Hospital, Almeria, Spain.6 Endocrinology private office, Granada, Spain.

\section{BACKGROUND}

New diabetes treatments, such as Lixisenatide, improve global metabolic status beyond glycemic control.

\section{AIM}

To evaluate lixisenatide effects on liver function, lipids and blood pressure levels in type 2 diabetes and obese patients attended in endocrinology offices in Andalusia (Spain).

\section{MATERIAL AND METHOD}

This is a prospective study with a sample of 106 patients with type 2 diabetes and obesity. In an intra-subject analysis, clinical and analytical data were evaluated at baseline and after Lixisenatide treatment.

\section{RESULTS}

We studied 106 patients (51.9\% women) with type 2 diabetes and obesity. Average age was $57.9 \pm 1.1$ years and average duration of diabetes was $11.1 \pm 0,7$ years. At baseline, $66 \%$ of the patients used insulin. We re-evaluated the patients $3.8 \pm 0.2$ months after treatment with Lixisenatide.

$\mathrm{BP}$ and lipids improvements were still significant in the hypertension and lipid treated subgroups (SBP, $p=0.001$; DBP,

$\mathrm{p}=0.005$; Total-Chol, $\mathrm{p}<0.001$, LDL-Chol, $\mathrm{p}=0.013$ and TG $p=0.014)$, while only the decrease of SBP $(p=0.036)$ remained significant in the subgroup of patients without hypertension or lipid-lowering therapy.
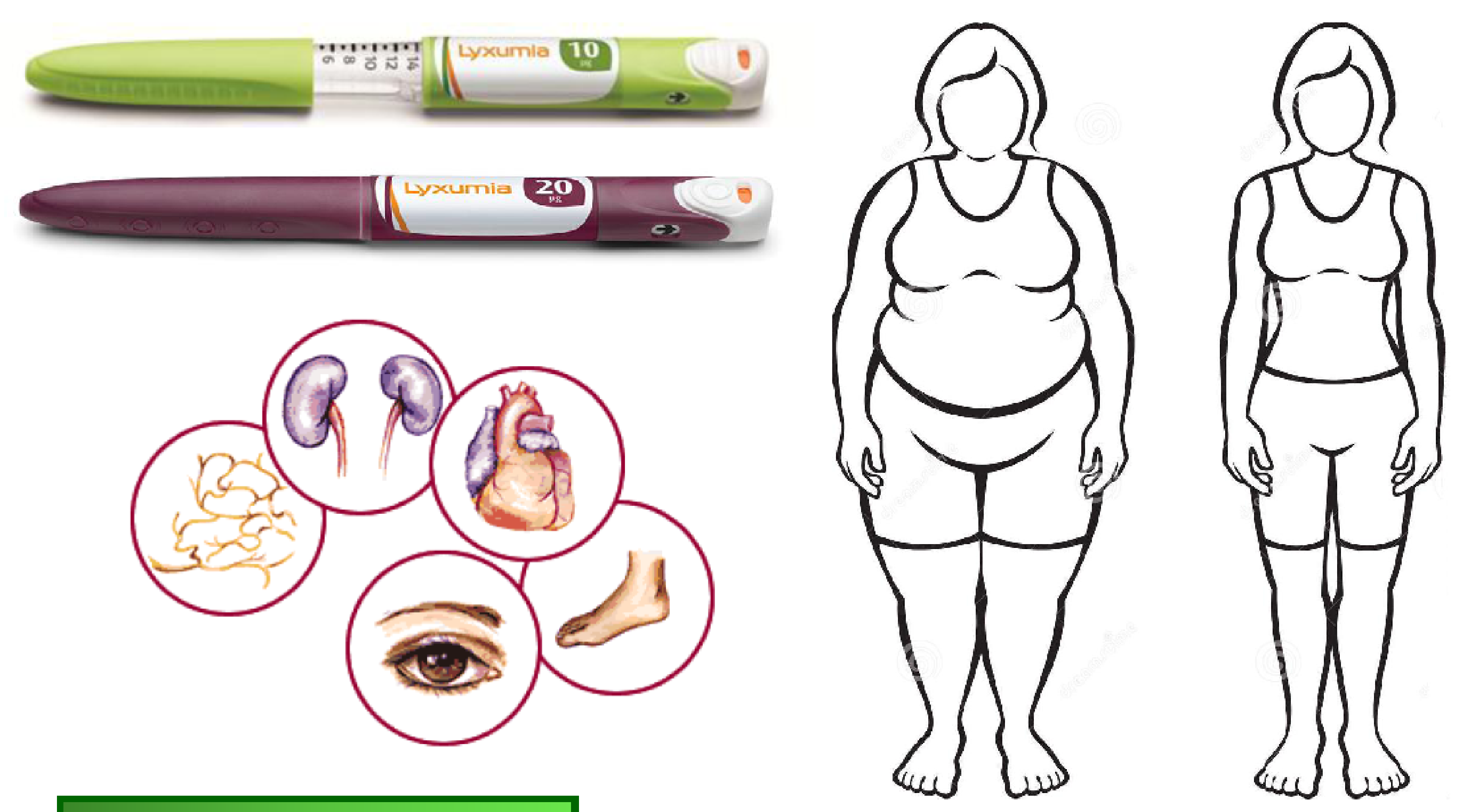

\section{CONCLUSIONS}

1. We found significant improvement of anthropometric parameters and glycemic control in terms of fasting glucose and HbA1c.

2. Significant decrease of BP, GOT and lipid profile and less insulin requirements were observed.

Table 1: Clinical and analytical variables pre- and post-treatment.

\begin{tabular}{|c|c|c|c|}
\hline Variable & Baseline & Lixisenatide & $\mathbf{P}$ \\
\hline Weight (kg) & $100.3 \pm 2.1$ & $96.7 \pm 2$ & $<0.001 *$ \\
\hline BMI (kg/m2) & $37.1 \pm 0.7$ & $35.9 \pm 0.6$ & $<0.001 *$ \\
\hline$W C(\mathrm{~cm})$ & $111.1 \pm 2.5$ & $104.7 \pm 2.6$ & $0.002^{*}$ \\
\hline SBP (mmHg) & $144.8 \pm 1.8$ & $137.8 \pm 2.3$ & $<0.001^{*}$ \\
\hline DBP (mmHg) & $83.3 \pm 1.3$ & $80.1 \pm 1.3$ & $0.001 *$ \\
\hline HR (bpm) & $83.6 \pm 1.7$ & $81 \pm 1.5$ & 0.934 \\
\hline Fasting glucose (mg/dL) & $191 \pm 6.6$ & $154.1 \pm 4.5$ & $<0.001 *$ \\
\hline HbA1c (\%) & $8.7 \pm 0.1$ & $7.8 \pm 0.1$ & $<0.001 *$ \\
\hline Total-Chol (mg/dL) & $181.9 \pm 3.6$ & $165.2 \pm 3.3$ & $<0.001 *$ \\
\hline LDL-Chol (mg/dL) & $98.2 \pm 3$ & $88.2 \pm 3.6$ & $0.040^{*}$ \\
\hline HDL-Chol (mg/dL) & $44.1 \pm 1.2$ & $45.7 \pm 1.2$ & 0.871 \\
\hline TG (mg/dL) & $221.6 \pm 17$ & $185.2 \pm 11.3$ & $0.047^{*}$ \\
\hline GOT (UI/L) & $28.5 \pm 1.9$ & $25.3 \pm 1.5$ & $0.022^{*}$ \\
\hline GPT (UI/L) & $35.8 \pm 2.9$ & $31.5 \pm 1.8$ & 0.084 \\
\hline GGT (UI/L) & $50.6 \pm 4.8$ & $48.3 \pm 4.3$ & 0.762 \\
\hline $\mathrm{AF}(\mathrm{mU} / \mathrm{mL})$ & $77.3 \pm 3.7$ & $76.4 \pm 3.4$ & 0.680 \\
\hline $\begin{array}{l}\text { Albumin/creatinine ratio } \\
\text { (mg/L) }\end{array}$ & $20 \pm 5.4$ & $15.1 \pm 3.1$ & 0.876 \\
\hline $\begin{array}{l}\text { Albumin/creatinine ratio } \\
(\mathrm{mg} / \mathrm{g})\end{array}$ & $56.1 \pm 23.9$ & $31.2 \pm 12.4$ & 0.246 \\
\hline Insulin units & $36.5 \pm 3.5$ & $33.6 \pm 3.1$ & $0.045^{*}$ \\
\hline Hypertension drugs (\%) & 75.5 & 82 & $<0.001^{*}$ \\
\hline Lipids drugs (\%) & 70.8 & 81 & $<0.001^{*}$ \\
\hline
\end{tabular}

